\title{
A Capability Perspective on Performance Deficiencies in Utility Firms
}

\author{
Hagen Worch $^{a 1}$, Bernhard Truffer ${ }^{a}$, Mundia Kabinga ${ }^{b}$, Anton Eberhard ${ }^{b}$, Jochen Markard ${ }^{a}$ \\ ${ }^{a}$ Eawag - Swiss Federal Institute of Aquatic Science and Technology \\ Cirus - Innovation Research in Utility Sectors \\ Überlandstrasse 133, P.O. Box 611, 8600 Dübendorf, Switzerland \\ E-mail: hagen.worch@eawag.ch,bernhard.truffer@eawag.ch,jochen.markard@eawag.ch \\ ${ }^{b}$ University of Cape Town \\ Graduate School of Business, Management Programme in Infrastructure Reform \& Regulation \\ Breakwater Campus, Portswood Road, Cape Town, South Africa \\ E-mail: mundia.kabinga@gsb.uct.ac.za, anton.eberhard@gsb.uct.ac.za
}

\section{Working Paper}

Version: June 7, 2012

\begin{abstract}
Infrastructure services are crucially important in our economies. Despite this importance, utility firms have found little attention in management research. This is surprising because the lack of adequate organizational structures, skills and specialized managerial know-how is an emergent issue and main challenge for many utilities worldwide. We propose a capability-based framework to explain performance deficiencies in utilities as a result of policy and regulatory changes. The framework elaborates why capability gaps emerge and how this affects performance. The insights from this framework complement the conventional explanations of the transaction cost and agency approaches, which suggest that appropriate incentives and regulatory structures increase the performance of public utilities immediately or after a short adaptation process. In contrast, capability gaps - understood as an inadequate availability of competences, expertise and experience - tend to have long-lasting effects because capabilities take time to develop. Especially if capabilities are based on experience, correcting for a gap and rebuilding capabilities take time due to the involved learning processes. A crucial implication of the presented capability perspective is that performance deficiencies affect utility firms - and therefore the ability of infrastructure sectors to provide adequate services - more severely than expected by traditional approaches.
\end{abstract}

Keywords: Capability perspective, capability gaps, utilities, performance, infrastructure sector specificities, policy and regulatory change

JEL subject codes: J24, L32, L94, L95, M50

\footnotetext{
${ }^{1}$ Corresponding author
} 


\section{Introduction}

Infrastructure services such as electricity, water supply, sanitation and transportation are crucially important in our economies. Despite this importance and a large set of literature focusing on infrastructure regulation (e.g., Armstrong and Sappington 2006; Guthrie 2006; Gratwick and Eberhard 2008; Joskow 2008; Delmas, Russo, Montes-Sancho and Tokat 2009; Ménard 2009), the management of utility firms has found little attention in research. This is surprising because the lack of adequate organizational structures, skills and specialized managerial know-how is an emergent issue in different infrastructure sectors and a main challenge for many utility organizations worldwide (OECD 2006, 2007; Urban Land Institute and Ernst \& Young 2007). Utilities are confronted with substantial challenges in both, operating and managing the built infrastructure and strategic planning to maintain, renew and expand infrastructure assets to meet future demands (Gil and Beckman 2009).

Traditional explanations of performance deficiencies in infrastructure sectors have mainly applied principal-agent approaches and transaction cost economics. They have identified regulatory and contractual issues as main causes for inefficiencies and suggested changes in the incentive structures and institutional frameworks to improve performance (e.g., Joskow 2002; Gómez-Ibáñez 2003, 2007; Irwin and Yamamoto 2004; Armstrong and Sappington 2006; Guthrie 2006).

One of the underlying assumptions in the two approaches is that if appropriate incentives and regulatory structures are implemented, performance increases immediately or after a short adaptation process. However, in many countries infrastructure sector reforms are incomplete, have been implemented much slower than expected, experienced resistance from sector players, and even caused the reversal of the reform process (OECD 2006; Joskow 2008; Gratwick and Eberhard 2008). Consequently, the performance of utilities often declined further and led in some cases to substantial failures in providing infrastructure services (e.g., repeated electricity black outs). Thus, performance problems tend to become more severe and last for significantly longer time periods than expected by traditional approaches.

In this paper, we propose a capability-based framework to explain performance deficiencies in infrastructure sectors. The framework elaborates how policy and regulatory changes may create gaps between the required and available capability structure of utilities and how this, in turn, affects performance and the quality of service delivery. Applying a capability perspective enables us to assess some underlying reasons for performance deficiencies at the organizational level of utility firms, which traditional approaches find difficult to explain.

Research on the role of capabilities in utilities and infrastructure sectors has been limited so far. There are some exceptions. Research has shown that changes in the regulatory environment drive organizational restructuring processes, which affect the resource base of established utilities and result 
in a short-term decline of efficiency (Dyner and Larsen 2001; Delmas and Tokat 2005; Delmas, Russo, Montes-Sancho and Tokat 2009). On the other hand, sector deregulations have reduced restrictions allowing utilities to adopt new strategies (Gebauer, Worch and Truffer 2012; Worch, Kabinga, Eberhard and Truffer 2012 forthcoming) and build capabilities to improve environmental performance (Delmas, Russo and Montes-Sancho 2007; Delmas, Russo, Montes-Sancho and Tokat 2009). Other contributions have found that public utilities may overcome capability gaps by implementing appropriate strategic planning processes (Dominguez, Worch, Markard, Truffer and Gujer 2009). Another stream of research has highlighted how building specific capabilities to manage the regulatory environment influences the performance of utility firms (Bonardi, Holburn and Vanden Bergh 2006; Holburn and Vanden Bergh 2008; Oliver and Holzinger 2008). We extend this line of research and advance the capability perspective to explain the emergence and persistence of performance deficits in utilities and infrastructure sectors.

In the following section, we introduce specific features that are characteristic for infrastructure sectors. In section 3, we briefly review which of the features are of major concern in the principal-agent and transaction cost economics literature to explain performance deficiencies. Section 4 introduces the capability argument. Then, we explain how the capability perspective provides a different rationale for how performance deficits can be explained in infrastructure sectors. Section 5 discusses the implications of the framework and concludes the paper.

\section{Infrastructure Sector Specificities}

Infrastructure sectors have several characteristic features. These are i) high capital needs, ii) specific investments with strong interdependencies between the different components of large technical systems, iii) substantial economies of scale and scope with the networks forming a natural monopoly, and iv) basic service provision (Dominguez, Worch, Markard, Truffer and Gujer 2009, pp. 33-34; Spiller 2010, pp. 148-149; Künneke, Groenewegen and Ménard 2010; Markard 2011). In combination, these features produce five implications that distinguish infrastructure sectors from other industries.

First, infrastructure developments have high capital needs with long time frames to recover the investment costs. This implies that investments in infrastructure sectors are related to high uncertainties.

Second, investments in infrastructure sectors are highly specific. Physical infrastructures with networks and plants form large technical systems with strong interactions between the different components. Once the systems are built, they can be hardly used in another context than for the applications they were initially established. Consequently, the asset specificity is very high. This 
implies - in combination with the long amortization cycles - that there are significant path dependencies.

Third, economies of scale and scope are important features in infrastructure sectors. Economies of scale are particularly relevant in the context of physical networks. A physical network is the central feature that economists have used to define utility sectors and distinguish them from other industries. The fixed costs are high and the marginal costs of an extra unit of service delivery are low. Consequently, the average cost is significantly above the marginal cost to provide one unit of the utility good. A monopoly is the only market form that allows a company to operate under this cost structure productively. Thus, a monopolistic sector structure is an implication of this feature.

Besides substantial economies of scale, infrastructure sectors are assumed to have also economies of scope with advantages of coordinating different functions of the value chain (e.g., generation, transmission, distribution) or different utility services (e.g., water supply, wastewater, electricity) within one organization. This implies an advantage of larger utilities. However, the extent of economies of scope in infrastructure sectors is still under debate in the literature with unclear empirical results.

Fourth, infrastructure industries provide basic services. One implication is that utilities have in addition to providing services effectively and efficiently also to accomplish other objectives often closely linked to and embedded in political processes. This includes delivering broadly accessible and affordable infrastructure services. Furthermore, environmental concerns are increasingly important, particularly in electricity generation, water supply and sanitation. Thus, utilities have to pursue multiple objectives.

Another implication of providing basic services is that utility organizations cannot just withdraw, if the service provision becomes difficult or even economically not viable. Utilities cannot strategically change and adopt better business opportunities, which are unrelated to the task of providing the basic services. Utilities have also not the option to specialize in the most profitable areas. For instance, a power utility can hardly decide to cut down supply substantially and only generate and supply electricity from the sources with the highest margins. Or a local wastewater utility cannot opt to treat only industrial wastewater and cut down the sanitation services for private households because this would be a more profitable business. This distinguishes infrastructure sectors from other industries, where companies can generally change their strategic focus and disinvest in providing specific products and services, and decide for other ones. Utilities do not have this option. This implies that they have to adjust their operations and provide services under the given market, business and regulatory environment.

\section{Traditional Theoretical Approaches}


Principal-agent approaches and transaction cost economics have a long tradition in analyzing infrastructure sectors and explaining performance deficiencies. The two approaches emphasize asymmetric information as underlying reasons for opportunistic behavior of utility firms with the result that service delivery is poor. While principal-agent arguments see occurring problems predominantly due to the monopolistic position of utilities, transaction cost reasoning refers mainly to two other infrastructure sector specificities, namely high uncertainty and asset specificity. The two research traditions suggest optimal incentive mechanisms and adequate contractual and institutional designs to mitigate the asymmetric information problems and therefore opportunistic behavior. The implicit assumption is that implementing the right incentives and contractual mechanisms has a direct positive impact on the utilities' strategic behavior and ultimately on performance without a substantial time lag.

Table 1 summarizes the features of infrastructure sectors and outlines the derived implications as presented in section 2. The table further summarizes how different theoretical perspectives explain performance deficiencies as discussed in section 3 and 4 .

\subsection{Principal-Agent Approaches}

Traditional principal-agent approaches play a prominent role in analyzing infrastructure sectors (e.g., Baron and Myerson 1982; Joskow and Schmalensee 1986; Laffont and Tirole 1993; Armstrong and Sappington 2007). A main concern is the natural monopoly situation (cf. table 1). Since monopolies set prices too high, utilities need to be regulated. The need for regulation infers a principal-agent problem because of the prevailing asymmetric information between the regulator and the utility. The regulator tends to be less informed than the regulated monopolist about the demand of the services, the current cost structure, and the potentials for a lower future cost structure (Armstrong and Sappington 2006, p. 330; Fremeth and Holburn 2009). To deal with the asymmetric information in price setting, agency theory has suggested various incentive designs and an optimal regulatory framework. Policy makers may introduce competition into infrastructure industries or incentivize the monopolist to disclose the true costs of service delivery through rate of return or price cap regulation. Finding an adequate price setting mechanism is basically the attempt to balancing the trade-off between allowing the monopolist supplier sufficient rent and enforcing efficiency at the same time (Armstrong and Sappington 2006, 2007; Puller 2007).

In addition, principal-agent approaches have been applied to examine the role of regulation on investments (e.g., Guthrie 2006). The argument is that an inadequate regulatory framework generates asymmetric information and therefore may result in insufficient levels of investments. The investments can be too high but more likely to be too low. Thus, inadequate regulatory frameworks explain investment failures. This argument is in line with the property-rights theory (Grossman and 
Hart 1986; Hart and Moore 1990), which predicts that incomplete contracts due to asymmetric information distort investment decisions ex-ante and therefore lead to underinvestments.

In addition to concerns about the monopolistic situation, another line of principal-agent research assesses the procurement of contracts between utilities and their suppliers. A prominent example is the coal-contracting of electricity utilities with the choice between long-term versus armslength contracts (Michaels 2006). Research has indicated that the more specific the coal requirements for power generation are, and hence the more difficult it becomes to mitigate information asymmetries about coal quality, the more likely it is that coal supply and generation are integrated.

Finally, principal-agent approaches are applied to analyze various aspects of the shareholdermanagement relation. Important topics include the various forms of management contracts between the shareholders, which are often municipal, provincial or national governments, and the utility service providers (Gómez-Ibáñez 2003). Also performance contracts gain increasingly interest and are assessed with a principal-agent lens (Gómez-Ibáñez 2006, 2007).

\subsection{Transaction Cost Economics}

The transaction cost economics literature has extensively researched phenomena in infrastructure sectors particularly in electricity sectors (e.g., Joskow 2002; Spiller and Tommasi 2005). Transaction cost reasoning assumes - similarly to principal-agent arguments - that asymmetric information generates problems, which lead to suboptimal performance outcomes. Main concerns of the transaction cost approach are uncertainty and high asset specificity, which are both typical features of infrastructure sectors (cf. table 1). High uncertainty and asset specificity induce hold-up problems. Hold-up problems occur in interactions between different players in infrastructure sectors (e.g., between generators and coal suppliers, utilities and the regulator, and/or the regulator and policy makers). Adequate contractual and institutional designs are assumed to have a direct impact and be effective immediately.

A key area of transaction cost economics inspired research in utility sectors is to analyze the trade-off between mitigating hold-up problems through contracts that are as detailed as possible, and at the same time leave enough space for contract partners to adjust to changes caused by the high uncertainty in the sector (Tadelis 2009). For example, the procurement problem refers to the situation in which a utility has to balance the incentive to reduce costs and improve efficiency versus the incentive to remain flexible enough to adopt to changes and therefore avoid costly renegotiations under uncertainty. In this sense, the transaction cost approach addresses the trade-off between static efficiency and dynamic efficiency. Established regulatory frameworks address often only one side of the trade-off. Competitive bidding tends to solve the efficiency problem but fails to respond optimally 
to ex post adaptation. In contrast, cost-plus approaches tend to respond to emerging changes after signing the contract but efficiency losses occur.

Similar contractual issues occur in other areas of utility management. This includes investment contracts, processes of contracting out but also to running and operating utilities. For all these functions applies that contract partners may approach these issues by choosing between different contract options (see Gómez-Ibáñez 2003, p. 33).

Recent contributions have also applied transaction cost arguments to address the infrastructure sector feature that utilities provide basic services and have therefore often to pursue multiple objectives (Spiller 2010). The concern in this line of research is that governments through regulatory agencies can hold-up utilities by threatening them to change the regulatory framework. Similarly, informed third parties tend to influence the regulatory framework by shaping the policy process to their advantage by exploiting the asymmetric information situation. In contrast to most principal agent and some of the more traditional transaction cost approaches, this line of literature does not assume that governments and regulatory agencies can contribute to solve asymmetric information, high uncertainty and asset specificity. It rather argues that government agencies are one major source of problems in infrastructure sectors. The implication from a transaction cost perspective is to set up adequate institutional conditions.

Table 1 about here

\section{A Capability-Based Framework for the Analysis of Utility Firms}

\subsection{Capability Approach}

In this section, we introduce a capability-based framework to explain performance deficiencies in utility firms. Organizational capabilities have been extensively discussed in the management literature (e.g., Barney 1991; Teece, Pisano and Shuen 1997; Newbert 2007; Barney, Ketchen Jr. and Wright 2011). In line with this literature, we define capabilities as competences and skills to perform distinctive activities and tasks in organizations.

To explain performance deficiencies, a capability gap is an important conceptualization in the presented framework (Lavie 2006; Worch, Truffer, Kabinga, Markard and Eberhard 2012). It is defined as the insufficient availability of knowledge, expertise and experience in an organization. Capability gaps emerge, if the existing capabilities diminish while a task remains largely unaltered. Or alternatively, a mismatch may occur if changes in a task lead to increased requirements that cannot be 
met with the available capabilities. A capability gap implies that a task is achieved in a quantity or quality, which is lower than defined. Thus, the performance declines.

While principal-agent approaches and transaction cost economics explain performance deficits through insufficient contracts, the capability perspective explains deficiencies through the loss of capabilities. The key mechanism for emerging capability gaps is that policy and regulatory changes affect the existing and/or required capability structure of utilities. The impact on a firm's capabilities may occur through the introduction of new public policy programs (e.g., requiring generation portfolios with more renewable energy sources), regulatory changes (e.g., requiring unbundling of the transmission grid from generation, or the liberalization of electricity wholesale markets) and technological innovations (e.g., new generation technologies, or smart meters). We argue that these changes tend to alter the specific characteristic of the infrastructure sector features. For example, policy and regulatory changes may increase uncertainty. They may also change the economies of scale and scope, or introduce additional objectives for utilities to achieve. As utilities can hardly adjust to such changes immediately - especially when the changes are unexpected or require capabilities that are based on long-term experience - we expect capability gaps to emerge at the organizational level and to affect the performance of utilities. In the following, we describe in more detail how capability gaps emerge as a result of policy and regulatory changes (cf. table 1).

\subsection{Infrastructure Sector Specificities and Capability Gaps}

\section{High uncertainty}

One reason for capability gaps to occur is an increasing uncertainty of the business and regulatory environment. High uncertainty about recovering investment costs and the future technological development are specifically prevalent in infrastructure sectors because the physical networks, assets and technical systems require high investments and have long amortization periods. If uncertainty is relatively low, it tends to be less difficult for a utility to identify and define the required capability structure to perform the defined tasks. High uncertainty makes it more difficult to determine the required capability configuration. This is because a utility has to build, implement and manage capabilities so that they cover an increasing number of contingencies that might occur.

Consequently, a utility would need to establish a capability structure with substantial excess capabilities quantitatively and qualitatively. However, it is barely feasible for a utility to provide an adequate capability structure for all potential contingencies. Thus, the higher the uncertainty of the market and regulatory environment is, the higher is the possibility of a mismatch between existing and required capabilities and therefore of a capability gap.

For example, if carbon emissions policies remain unclear whether to demand in the future from electricity suppliers to mandatorily build renewable generation capacities or establish carbon 
capture facilities or compensate emissions with tradable certificates (or a combination of these means), then there is a higher possibility for an emerging capability gap than under a policy that precisely defines the implementable means, for which utilities can specifically build capabilities.

From a transaction cost perspective, high uncertainty induces hold-up problems between contract partners with the corresponding frictions and costs. From a capability perspective, high uncertainty implies that there is a large number of possible contingencies about how the business environment develops and capability gaps are likely to emerge. Thus, even if the asymmetric information situation causing hold-up problems is solved through adequate institutional settings, uncertainty tends still to produce capability gaps in utilities, which result in a diminished performance. As this example shows, applying a capability perspective provides an additional explanation for performance problems in infrastructure sectors. It shifts the focus from contractual concerns to the composition of competences and skills as drivers of firm performance.

\section{Strong interdependencies}

Highly specific investments with strong interdependencies between the components of the large technical systems are another typical feature of infrastructure sectors. The interdependencies are most prominent between the production and network assets with joint operation creating substantial synergies. Because of these interdependencies, it is difficult to separate the workforce into different functional areas or even across firm boundaries.

If changes in the regulatory framework separate hitherto integrated functional areas so that joint operations are hardly possible or even restricted, capability gaps emerge. This is because the necessary capabilities for understanding the interdependencies to jointly operate the separated functional areas across organizational boundaries tend to get lost. Thus, even if the capability structure is fully available to achieve the tasks in each functional area, capability gaps emerge because the specific knowledge about the joint operation of the functions is no longer sustained across the firm boundaries.

The more a regulatory framework requires the separation of functional areas with high interdependencies, the higher is the potentially emerging capability gap. This is for example the case, when integrated utilities have to unbundle the power plant and transmission grid operations. Unbundling separates two traditionally closely linked functional areas. This disconnects capabilities, which tend to be critical to operate these two functions adequately.

\section{Economies of scale of large technical systems}

Economies of scale and scope are a characteristic feature of infrastructure sectors because of the large technical systems that service providers typically operate. Large technical systems tend to 
have long life cycles with each life cycle phase requiring a specific capability structure (e.g., planning, building, operating and refurbishing). As the required capability structures change continuously during the life cycle, capability gaps potentially emerge in the shift from one to the other of these phases. Thus, the more relevant economies of scale and scope and the longer the corresponding life cycles of the technical systems, the higher is the possibility of major mismatches between existing and required capabilities and therefore of a capability gap.

\section{Multiple objectives}

The infrastructure sector specificity of providing basic services implies that utilities pursue multiple objectives. From a capability perspective, tensions occur between the competing objectives because the various objectives require different capability structures. For example, an electricity provider may aim at generating cheap electricity from fossil fuels to serve its power-intensive industrial customers. At the same time, the utility might pursue a strategy to establish itself as a leading renewable electricity provider. Building the required capability structure for one of the objectives may not cover the required capability structure of another one. Thus, the more objectives a utility has to pursue, the more likely is that a capability gap emerges for at least one or several of the multiple goals.

The problem of a capability gap intensifies when further objectives are added. Then, the required capability structure changes substantially. This is the case, if utilities or policy makers identify new tasks or shift and expand priorities of existing tasks. For example, in addition to provide secure and efficient infrastructure services, a newly established public policy program may demand to deliver services with a specific technology mix to reduce environmental impact, which then requires a different set of capabilities. An illustration is the shift of the Japanese energy policy toward a less nuclear power dominated generation portfolio after the Fukushima disaster. This implies a massive shift in the required capabilities within the electricity sector from knowledge on nuclear power technologies toward expertise in renewable electricity generation technologies. Another example would be the paradigmatic change from central municipal wastewater treatment plants to decentralized systems, which require a different set of capabilities to install, operate and maintain water utility services. Thus, the more new tasks diverge from the current ones, the more likely is the emergence of a capability gap.

Furthermore, the required capability structure also changes, if the task itself remains largely unaltered but the conditions under which it is operated changes. For example, policy intervention may put the building of new production capacities on halt or even cause a decline of a sector's capacities (e.g., electricity generation capacities). Tightened power generation capacities tend to necessitate altered operation procedures to supply services. This requires additional capabilities compared to a 
situation with sufficient generation capacities. Additional capabilities would include more personnel to run power plant operations, for intensified surveillance of the generation process and increased maintenance activities. Thus, the more the conditions for accomplishing defined tasks change, the more likely is the emergence of a capability gap.

A capability gap also emerges when the tensions due to the pursuit of multiple goals affect the actual capability structure directly, so that capabilities are lost. This is for example the case, if new policies may require outsourcing specific activities or sub-contracting with specific supplier groups. These influences tend to render the organizations' actual capability structures inadequate. Thus, the stronger the external impact to change the current prioritization of objectives, the more likely is a temporary mismatch between the required and existing capabilities.

Pursuing multiple objectives may also lead to unclear priorities within an organization. As a result, the capability accumulation may focus on specific objectives but pay less attention to others. Consequently, the actual capability structure diverges from the required capability structure for those tasks. Thus, the higher the ambiguity of the objectives' priorities, the more likely is the emergence of a capability gap.

\section{Limited options for strategic reorientation}

Another implication of providing basic services is that utilities have limited options for strategic reorientation and specialization. As utilities are commissioned to provide basic services, their freedom in responding to performance deficiencies is limited. In fact, it is only possible through building and acquiring capabilities but largely unfeasible through strategic change and employing the existing capabilities in a different way. Thus, if the range of options for adjustments is highly limited, a mismatch between the required and existing capabilities tend to occur.

Due to this strategic inflexibility, capability gaps may also occur - possibly less often - in the opposite direction. In the case that utilities have more competences and skills available than required, the costs of performing the task tend to be too high. While companies in non-infrastructure sectors aim to fully employ the available capabilities, utilities have limited options to leverage on their organizational resources and capabilities - even if the available capabilities are underemployed. They have hardly the option to change the business model and switch the strategic focus to different products and services, diverge from the delivery of basic goods and specialize in different areas of service supply. Thus, utilities have to provide the services, even if they do not have the sufficient capability structure or if they have a capability structure that could be leveraged more efficiently and financially more viable in a different product, service and geographical context. The feature to provide basic services restricts utilities to exploit their capabilities within a defined set of business activities and the determined geographical area. This prevents performance improvements, as 
available capabilities remain unused to improve efficiency by taking advantage of potential economies of scale and scope.

\section{Conclusions}

We have argued that public policy and regulatory changes cause systematic changes of the existing and required capability structures of utilities. This results in capability gaps with the corresponding performance decline. A capability perspective on the performance of utility firms complements conventional approaches in two ways. First, the principal-agent and transaction cost approach have in common that they understand performance failure mainly as a result of contractual issues occurring in the interactions between utilities and their environment, i.e. customers, suppliers, regulators and governmental institutions. Agents behave opportunistically within utilities and across firm boundaries and search permanently to exploit asymmetric information to their own advantage. From this perspective, it is sufficient to implement adequate contractual and institutional structures to incentivize optimal contracts, prices and investments and therefore to improve performance.

This, however, is not sufficient from a capability perspective because even under optimal institutional conditions can capability structures be inadequate for reasons discussed in the previous chapters. The traditional approaches' search for the best design structures has been at the expense of understanding the incentivized tasks themselves. Contracting, price setting and investing are tasks, which require adequate skills and competences. In a capability perspective, it is central to understand how the required composition of capabilities can be built and maintained to perform these tasks. The logic of our argument therefore differs from the traditional explanations as it resorts on the coordination problem to configure and sustain adequate knowledge structures. It sheds a different though complementary - light on the management and regulation of utility firms and goes beyond the mere focus on mitigating asymmetric information and opportunistic behavior.

A second implication of a capability perspective is to explain the persistence of performance deficiencies in utilities. Principal-agent and transaction cost reasoning expects the performance to improve fast, if the implemented contractual and institutional designs are adequate. We assert that it takes - partly extensive - time and effort for a utility to respond to an emerging capability gap and accumulate the required set of skills and competences. Rebuilding and acquiring capabilities takes even more time and requires specific implementation strategies, if knowledge is based on long-term experience. For example, if accomplishing a specific task requires extensive experience, it is hardly possible to acquire the capabilities externally. They rather need to be built internally in a learning-bydoing process. Thus, focusing on the underlying processes of transforming capability structures provides more adequate explanations about the existence and persistence of performance deficits even 
under conditions of allegedly improved incentive structures and context conditions. In this sense, we provide an explanation why utilities may show persistent problems in regaining adequate performance levels for the provision of services, even if effective incentive mechanisms are promptly established.

Summarizing this paper, a central insight from applying a capability perspective is to explain performance deficiencies in utilities as a result of policy and regulatory changes. These changes tend to alter the characteristics of the infrastructure sector specific features, which in turn influence the utilities' capability structures. Consequently, capability gaps emerge and performance declines. A second key insight is that performance deficiencies may persist. This is because of the effort and time it takes to regain lost competences and skills, and adjust the capability structure. To close the capability gap, a utility firm has to initiate processes of capability maintaining, reconfiguring and building. Such responses are hardly effective immediately or even in the short-term. Utilities have to operate with sub-optimal and inadequate capability structures and perform the full range of operations necessary to deliver the basic services. Therefore, a capability gap persists at least temporarily with the corresponding performance implications until the utility firm manages to reestablish an adequate portfolio of knowledge, expertise and experience. We believe more generally that the capability perspective offers a more balanced approach for understanding the cause and extent of performance deficiencies. Such an understanding provides a first step toward developing more effective strategies for solving inefficiencies in infrastructure sectors. This new perspective may therefore contribute some potentially important insights and advises for utility managers, regulators and policy makers. 


\section{Acknowledgments}

The authors greatly acknowledge financial support from the Swiss South African Joint Research Programme (SSAJRP), Project No.7. Part of the work was conducted while one of the authors (Bernhard Truffer) was a Fellow in the Sustainability Science Program at the Harvard Kennedy School. 
A Capability Perspective on Performance Deficiencies in Utility Firms - Working Paper, June 7, 2012

\section{Tables}

\begin{tabular}{|c|c|c|c|c|}
\hline \multirow{2}{*}{$\begin{array}{l}\text { Infrastructure sector } \\
\text { specific features }\end{array}$} & \multirow[t]{2}{*}{ Implications } & \multicolumn{3}{|c|}{ Explanations for performance issues } \\
\hline & & Principal agent approach & Transaction cost economics approach & Capability-based approach \\
\hline $\begin{array}{l}\text { High investment needs } \\
\text { with long time frames }\end{array}$ & $\begin{array}{l}\text { High uncertainty about } \\
\text { - Recovering investment } \\
\text { costs } \\
\text { - Continued applicability of } \\
\text { established technologies }\end{array}$ & $\%$ & $\begin{array}{l}\text { Hold-up problems between contract } \\
\text { partners } \\
\text { (Joskow 2002; Spiller and Tommasi 2005) }\end{array}$ & $\begin{array}{l}\text { Large number of potential contingencies due to changes of the } \\
\text { market conditions and the business environment: } \\
\text { Capability gaps because it is unfeasible to build the required } \\
\text { capability structure for all possible contingencies }\end{array}$ \\
\hline $\begin{array}{l}\text { Highly specific } \\
\text { investments with strong } \\
\text { interdependencies }\end{array}$ & $\begin{array}{l}\text { - High asset specificity } \\
\text { - Path dependencies }\end{array}$ &. & $\begin{array}{l}\text { Hold-up problems between contract } \\
\text { partners } \\
\text { (Joskow 2002; Spiller and Tommasi 2005) }\end{array}$ & $\begin{array}{l}\text { Work force not easily separable into different functional areas } \\
\text { or across firm boundaries due to interdependencies: } \\
\text { Capability gaps if functional areas are organizationally too } \\
\text { strongly separated }\end{array}$ \\
\hline $\begin{array}{l}\text { Economies of scale and } \\
\text { scope, and physical } \\
\text { networks }\end{array}$ & $\begin{array}{l}\text { - Natural monopoly in } \\
\text { networks } \\
\text { - Advantages of large } \\
\text { utilities }\end{array}$ & $\begin{array}{l}\text { Principal-agent problems due to the } \\
\text { natural monopoly situation with an } \\
\text { impact on: } \\
\text { - Price setting } \\
\text { - Investments } \\
\text { - Procurement } \\
\text { (Baron and Myerson 1982; Armstrong } \\
\text { and Sappington 2006; Guthrie 2006; } \\
\text { Michaels 2006; Puller 2007) }\end{array}$ &. & $\begin{array}{l}\text { Large technical systems tend to have long life cycles with each } \\
\text { life cycle phase requiring a specific capability structure: } \\
\text { Capability gaps because required capability structures change } \\
\text { continuously during the life cycle }\end{array}$ \\
\hline \multirow[t]{2}{*}{ Provide basic services } & Multiple objectives & $\begin{array}{l}\text { Principal-agent problems because of } \\
\text { management contracts between } \\
\text { shareholders and utilities } \\
\text { (Gómez-Ibáñez 2003, 2007) }\end{array}$ & $\begin{array}{l}\text { Hold-up problems as governments and/or } \\
\text { interested third parties may threaten to } \\
\text { change regulations } \\
\text { (Spiller 2010) }\end{array}$ & $\begin{array}{l}\text { Multiple objectives compete simultaneously for different } \\
\text { capability structures: } \\
\text { Capability gaps because of tensions between competing } \\
\text { objectives with different required capability structures; shifts } \\
\text { in objectives intensify the gap by rendering the actual } \\
\text { capability structure inadequate }\end{array}$ \\
\hline & $\begin{array}{l}\text { Limited options for strategic } \\
\text { reorientation and } \\
\text { specialization }\end{array}$ & $\%$ &. & $\begin{array}{l}\text { Degree of freedom in responding to performance issues is } \\
\text { limited as the provision of basic services is given and not } \\
\text { available for strategic change (inflexibility of responses): } \\
\text { Capability gaps are more likely to emerge because of the } \\
\text { limited range of options for adjustments; responding to } \\
\text { performance issues is only possible through building and } \\
\text { acquiring capabilities but largely unfeasible through business } \\
\text { reorientation and specialization (i.e., employing the actual } \\
\text { capability structure in a different way) }\end{array}$ \\
\hline
\end{tabular}

Table 1: Features of infrastructure sectors and its relevance in different theoretical approaches 


\section{References}

Armstrong, M., \& Sappington, D. E. M. (2006). Regulation, Competition, and Liberalization. Journal of Economic Literature, 44(2): 325-366.

Armstrong, M., \& Sappington, D. E. M. (2007). Recent developments in the theory of regulation. In Mark Armstrong, \& R. Porter (Eds.), Handbook of Industrial Organization (Vol. 3). Amsterdam: NorthHolland.

Barney, J. (1991). Firm Resources and Sustained Competitive Advantage. Journal of Management, 17(1): 99120.

Barney, J. B., Ketchen Jr., D. J., \& Wright, M. (2011). The Future of Resource-Based Theory: Revitalization or Decline? Journal of Management, 37(5): 1299-1315.

Baron, D. P., \& Myerson, R. B. (1982). Regulating a Monopolist with Unknown Costs. Econometrica, 50(4): 911-930.

Bonardi, J.-P., Holburn, G. L. F., \& Vanden Bergh, R. G. (2006). Nonmarket strategy performance: Evidence from U.S. electric utilities. Academy of Management Journal, 49(6): 1209-1228.

Delmas, M., Russo, M. V., \& Montes-Sancho, M. J. (2007). Deregulation and environmental differentiation in the electric utility industry. Strategic Management Journal, 28(2): 189-209.

Delmas, M., \& Tokat, Y. (2005). Deregulation, governance structures, and efficiency: the U.S. electric utility sector. Strategic Management Journal, 26(5): 441-460.

Delmas, M. A., Russo, M. V., Montes-Sancho, M. J., \& Tokat, Y. (2009). Deregulation, efficiency and environmental performance: evidence from the electric utility industry. In Claude Ménard, \& Michel Ghertman (Eds.), Regulation, Deregulation, Reregulation: Institutional Perspectives: 170-195. Cheltenham \& Northamption, MA: Edward Elgar.

Dominguez, D., Worch, H., Markard, J., Truffer, B., \& Gujer, W. (2009). Closing the Capability Gap: Strategic Planning for the Infrastructure Sector. California Management Review, 51(2): 30-50.

Dyner, I., \& Larsen, E. R. (2001). From planning to strategy in the electricity industry. Energy Policy, 29(13): 1145-1154.

Fremeth, A., \& Holburn, G. L. F. (2009). Information asymmetries and regulatory rate-making: case study evidence from Commonwealth Edison and Duke Energy rate reviews. In Claude Ménard, \& Michel Ghertman (Eds.), Regulation, Deregulation, Reregulation: Institutional Perspectives: 268-288. Cheltenham \& Northamption, MA: Edward Elgar.

Gebauer, H., Worch, H., \& Truffer, B. (2012). Absorptive capacity, learning processes and combinative capabilities as determinants of strategic innovation. European Management Journal, 30(1): 57-73.

Gil, N., \& Beckman, S. L. (2009). Infrastructure Meets Business: Building New Bridges, Mending Old Ones. California Management Review, 51(2): 6-29.

Gómez-Ibáñez, J. A. (2003). Regulating Infrastructure: Monopoly, Contracts, and Discretion. Cambridge, Massachusetts, and London: Harvard University Press.

Gómez-Ibáñez, J. A. (2006). Alternatives to Privatization Revisited: The Options for Infrastructure, Working paper prepared for the World Bank, April 2006.

Gómez-Ibáñez, J. A. (2007). Alternatives to Infrastructure Privatization Revisited: Public Enterprise Reform from the 1960s to the 1980s, Policy Research Working Paper No. 4391, World Bank, November 2007.

Gratwick, K. N., \& Eberhard, A. (2008). Demise of the standard model for power sector reform and the emergence of hybrid power markets. Energy Policy, 36(10): 3948-3960.

Grossman, S. J., \& Hart, O. D. (1986). The Costs and Benefits of Ownership: A Theory of Vertical and Lateral Integration. Journal of Political Economy, 94(4): 691-719.

Guthrie, G. (2006). Regulating Infrastructure: The Impact on Risk and Investment. Journal of Economic Literature, 44(4): 925-972.

Hart, O., \& Moore, J. (1990). Property Rights and the Nature of the Firm. Journal of Political Economy, 98(6): 1119-1158.

Holburn, G. L. F., \& Vanden Bergh, R. G. (2008). Making friends in hostile environments: Political strategy in regulated industries. Academy of Management Review, 33(2): 521-540.

Irwin, T., \& Yamamoto, C. (2004). Some Options for Improving the Governance of State-Owned Electricity Utilities, Energy and Mining Sector Board Discussion Paper No. 11, World Bank, February 2004.

Joskow, P. L. (2002). Electricity sector restructuring and competition: a transaction-cost perspective. In Eric Brousseau, \& Jean-Michel Glachant (Eds.), The Economics of Contracts: Theories and Applications: 503-530. Cambridge: Cambridge University Press. 
Joskow, P. L. (2008). Lessons Learned From Electricity Market Liberalization. Energy Journal, 29(Special Issue 2): 9-42.

Joskow, P. L., \& Schmalensee, R. (1986). Incentive Regulation for Electric Utilities. Yale Journal on Regulatioin, 4(1): 1-49.

Künneke, R., Groenewegen, J., \& Ménard, C. (2010). Aligning modes of organization with technology: Critical transactions in the reform of infrastructures. Journal of Economic Behavior \& Organization, 75(3): 494-505.

Laffont, J.-J., \& Tirole, J. (1993). A Theory of Incentives in Regulation and Procurement. Boston, MA: MIT Press.

Lavie, D. (2006). Capability reconfiguration: An analysis of incumbent responses to technological change. Academy of Management Review, 31(1): 153-174.

Markard, J. (2011). Transformation of Infrastructures: Sector Characteristics and Implications for Fundamental Change Journal of Infrastructure Systems, 17(3): 95-136.

Ménard, C. (2009). From technical integrity to institutional coherence: regulatory challenges in the water sector. In Claude Ménard, \& Michel Ghertman (Eds.), Deregulation, efficiency and environmental performance: evidence from the electric utility industry: 83-108. Cheltenham \& Northamption, MA: Edward Elgar.

Michaels, R. J. (2006). Vertical Integration and the Restructuring of the U.S. Electricity Industry Policy Analysis, No. 572, Cato Institute.

Newbert, S. L. (2007). Empirical research on the resource-based view of the firm: an assessment and suggestions for future research Strategic Management Journal, 28(2): 121-146.

OECD (2006). Infrastructure to 2030: Telecom, Land Transport, Water and Electricity. Paris: OECD Publishing.

OECD (2007). Infrastructure to 2030 (Volume 2): Mapping Policy for Electricity, Water and Transport. Paris: OECD Publishing.

Oliver, C., \& Holzinger, I. (2008). The effectiveness of strategic political management: A dynamic capabilities framework. Academy of Management Review, 33(2): 496-520.

Puller, S. L. (2007). Pricing and Firm Conduct in California's Deregulated Electricity Market. Review of Economics and Statistics, 89(1): 75-87.

Spiller, P. T. (2010). Regulation: A Transaction Cost Perspective. California Management Review, 52(2): $147-$ 158.

Spiller, P. T., \& Tommasi, M. (2005). The Institutions of Regulation: An Application to Public Utilities. In Claude Menard, \& Mary M. Shirley (Eds.), Handbook of New Institutional Economics. Dordrecht: Springer.

Tadelis, S. (2009). Incentives and transaction costs in public procurement. In Claude Ménard, \& Michel Ghertman (Eds.), Regulation, Deregulation, Reregulation: Institutional Perspectives: 67-82. Cheltenham \& Northamption, MA: Edward Elgar.

Teece, D. J., Pisano, G., \& Shuen, A. (1997). Dynamic capabilities and strategic management. Strategic Management Journal, 18(7): 509-533.

Urban Land Institute, \& Ernst \& Young (2007). Infrastructure 2007: A Global Perspective. Washington, D.C.: ULI - the Urban Land Institute.

Worch, H., Kabinga, M., Eberhard, A., \& Truffer, B. (2012 forthcoming). Strategic Renewal and the Change of Capabilities in Utility Firms. European Business Review.

Worch, H., Truffer, B., Kabinga, M., Markard, J., \& Eberhard, A. (2012). Tackling the Capability Gap in Utility Firms: Applying Management Research to Infrastructure Sectors, CID Research Fellow and Graduate Student Working Paper No. 55. Center for International Development at Harvard University, January 2012. 